Original Article

\title{
Twist1 was detected in mesenchymal cells of mammary fibroadenoma and invasive components of breast carcinoma in rats
}

\author{
Satomi Funahashi ${ }^{1}$, Yasumasa Okazaki ${ }^{*}$, Hirotaka Nagai ${ }^{1}$, Shan Hwu Chew ${ }^{1}$, Kumiko Ogawa ${ }^{2}$, \\ Takeshi Toyoda ${ }^{2}$, Young-Man $\mathrm{Cho}^{2}$, and Shinya Toyokuni ${ }^{1}$ \\ ${ }^{1}$ Department of Pathology and Biological Responses, Nagoya University Graduate School of Medicine, 65 Tsurumai-cho, Showa-ku, \\ Nagoya, Aichi 466-8550, Japan \\ 2 Division of Pathology, National Institute of Health Sciences, 3-25-26 Tonomachi, Kawasaki-ku, Kawasaki, Kanagawa 210-9501, \\ Japan
}

\begin{abstract}
Fibroadenoma (FA) is a common mammary fibroepithelial tumor. The tumor size of the FA is increased by estrogen, progesterone, prolactin, and pregnancy, whereas it decreases after menopause. These observations in humans indicate that FA is hormone dependent. In rats, the most common mammary neoplasm is also FA. Expression levels of Twist1, a transcriptional regulator of epithelialmesenchymal transition, were examined in paraffin-embedded tissue sections of an experimental rat breast model to find physiological alternations coincident with reproductive hormonal changes. Twenty-three Fischer 344/Brown Norway F1 hybrid rats were used as 14to 16 -week-old adolescent rats $(n=3)$, pregnant rats $(n=4)$, and lactating rats $(n=6)$ in addition to rats over 100 -weeks-old that exhibited aging $(n=3)$ and FA $(n=7)$. Seventy-six cases of chemically induced breast carcinoma and two cases of FA in Sprague Dawley rats were also examined. Using tissue sections, we observed that Twist1-positive mesenchymal cells were predominantly located in the periductal region in adolescent and pregnant rats and in the terminal duct lobular unit in pregnant and elderly rats. Twist 1 was also expressed diffusely in the mesenchymal cells of FA rats. Twist1-positive cancer-associated mesenchymal cells were found more frequently in the invasive components of breast carcinomas than in intraductal components. The expressions of Twistl in mesenchymal cells were induced by physiological and pathological stimuli, suggesting the biological role of Twist 1 in tissue structure. Further study may reveal the role of Twist1 in mesenchymal cells of mammary glands in rats. (DOI: 10.1293/tox.2018-0029; J Toxicol Pathol 2019; 32: 19-26)
\end{abstract}

Key words: Twist1, fibroadenoma, mesenchymal cell, chemically induced breast carcinoma, rat model

\section{Introduction}

The incidence of mammary gland neoplasms, demonstrating benign or malignant clinical courses, is increasing. The most frequent benign neoplasm is fibroadenoma (FA), which is presumed to arise from the terminal duct lobular unit (TDLU) area and to be enlarged by estrogen, progesterone, and prolactin in humans ${ }^{1,2}$. The characteristic histopathology of FA is a biphasic tumor, featuring the proliferation of both epithelial and mesenchymal elements. As much as $50-60 \%$ of FA has been shown to harbor point mutations in codon 44 of exon 2 of mediator complex subunit $12(M E D 12)^{1,3,4}$. Genomic analysis of laser microdissected

Received: 11 May 2018, Accepted: 3 August 2018

Published online in J-STAGE: 1 September 2018

*Corresponding author: Y Okazaki

(e-mail: samasuya@med.nagoya-u.ac.jp)

(C2019 The Japanese Society of Toxicologic Pathology

This is an open-access article distributed under the terms of the Creative Commons Attribution Non-Commercial No Derivatives (C) ${ }_{\text {BY NG ND }}$ creativecommons.org/licenses/by-nc-nd/4.0/). tissue samples revealed that the MED12 mutation was positive in stromal cells, but not in epithelial cells ${ }^{4}$, indicating that mesenchymal cells are critical for tumorigenesis in FA.

In rodents at puberty (approximately 3 weeks of age), ovarian hormones cause rapid proliferation and invasive growth, and the final developmental fate of the mammary gland is fulfilled only when pregnancy and lactation occur. The developing mammary gland model incorporates many of the properties associated with tumor progression, including invasion, reinitiation of cell proliferation and resistance to apoptosis and angiogenesis ${ }^{5}$, thereby allowing it to mimic the early tumor-progressive microenvironment.

In the present study, we explored the expression level of Twistl that is thought to be an essential player in mesoderm differentiation and epithelial-mesenchymal transition $^{6}$. Breast tissue is unique in that it continually changes its structure throughout the lifespan due to reproductive hormones, and thus, expression levels of Twistl were examined in non-tumor-bearing mammary glands of adolescent, pregnant, lactating, and elderly rats to compare the histopathology with endogenous hormonal changes. FA, which is the most common and hormone dependent benign neoplasm of the mammary gland ${ }^{7-12}$, was also examined. F1 hybrid 
rats were used because seven cases of spontaneous FA were produced in another experiment ${ }^{13}$. In addition, we examined the expression levels of Twistl in chemically induced breast carcinoma in Sprague Dawley (SD) rats ${ }^{14}$. In the present study, we detected Twistl-positive mesenchymal cells in the periductal area as well as in the TDLU area of pregnant rats, in the periductal area of adolescent rats, and in the TDLU area of elderly rats. Twistl was diffusely detected in the mesenchymal cells of FA, and the emergence of Twist1positive mesenchymal cells favored an invasive component over an intraductal component in chemically induced breast carcinomas in SD rats.

\section{Materials and Methods}

\section{Chemicals}

An antibody against Twistl (clone Twist2Cla, cat no. sc-81417) was purchased from Santa Cruz Biotechnology (Dallas, TX, USA). Histofine Simple Stain Rat Max PO (MULTI) was obtained from Nichirei Biosciences (Tokyo, Japan). Antibodies against calponin (clone CALP1, code no. M3556), p63 (clone 4A4, code no. M7247), $\alpha$-smooth muscle actin (SMA; clone 1A4, code no. M0851), desmin (clone D33, code no. M0760), BCIP/NBT substrate system (code no. K0598) and liquid DAB+ (code no. K3468), were obtained from DAKO Japan (Tokyo, Japan). Antibodies against Ki67 (clone MM1, NCL-Ki67-MM) and CD10-270 (clone 56C6, NCL-CD10-270) were purchased from Leica Microsystems (Tokyo, Japan). An antibody against cytokeratin (AE1/AE3, cat no. MS-343-P0) was purchased from Thermo Fisher Scientific (Waltham, MA, USA). TACS Blue Label was purchased from Trevigen (Gaithersburg, MD, USA). Immunosaver was purchased from Nisshin EM (Tokyo, Japan). Anti-mouse and anti-rabbit IgG (H+L) conjugated to alkaline phosphatase (cat no. 018-18091) and all of the other chemicals were of the highest quality available from Wako Pure Chemical Industries (Osaka, Japan).

\section{Animal experiments}

The Animal Care Committee of the Nagoya University Graduate School of Medicine approved these experiments. The care and handling of the animals were in accordance with the National Institutes of Health Guidelines. F1 hybrid rats were bred in-house by crossing the Fischer344 (F344; female) and Brown-Norway (BN/CIL; male) strains (Charles River Laboratories Japan, Yokohama, Japan). Rodents were housed in a temperature-controlled setting $\left(25^{\circ} \mathrm{C}\right.$ with alternating 12-h light/12-h dark cycles) and were allowed free access to distilled water and standard chow diet (Funahashi F-1, Chiba, Japan) during the experiment. A total of 23 F1 rats were used for the following experiments. Fourteen- to sixteen-week-old rats were used in the adolescents $(n=3)$, pregnant $(n=4)$, and lactating $(n=6)$ groups. The rats were euthanized at 9-12 days of pregnancy or at 2-4 days of lactation. As previously reported ${ }^{13}, 15$, rats over 100 week old were euthanized after developing FA $(n=7)$, as were elderly rats $(n=3)$ (Table 1). After euthanization by cervical disloca-
Table 1. Mammary Glands of F1 Hybrid Rats Used in This Study

\begin{tabular}{lc}
\hline Experimental group & Mammary glands of F1 hybrid rats \\
\hline Adolescence & 3 \\
Pregnancy & 4 \\
Lactation & 6 \\
Elderly & 3 \\
Fibroadenoma (FA) & 7 \\
\hline
\end{tabular}

Table 2. Mammary Tumors of Sprague Dawley Rats Used in This Study

\begin{tabular}{lc}
\hline Histopathological diagnosis & $\begin{array}{c}\text { Chemically induced mammary } \\
\text { tumors of Sprague Dawley rats }\end{array}$ \\
\hline Fibroadenoma (FA) & 2 \\
Ductal carcinoma in situ (DCIS) & 1 \\
Invasive breast carcinoma (IBC) & 8 \\
with intraductal component & 67 \\
IBC & 67 \\
\hline
\end{tabular}

tion, the mammary glands were excised and were immediately fixed in PBS-buffered 10\% formalin.

In female SD rats, breast carcinomas were induced by three chemical carcinogens as previously reported ${ }^{14}$. Briefly, $N$-bis (2-hydroxypropyl) nitrosamine (DHPN) $(2,800$ $\mathrm{mg} / \mathrm{kg}$ ) was administered once subcutaneously at 6 weeks of age. Next, 7,12-dimethylbenz(a)anthracene (DMBA) (50 $\mathrm{mg} / \mathrm{kg}$ ) was administered once orally at 7 weeks of age. Finally, acrylamide (40 ppm) was administered in drinking water for 22 weeks. We examined 78 cases as follows: 2 cases of FA, 1 case of ductal carcinoma in situ (DCIS), 8 cases of invasive breast carcinoma (IBC) with intraductal component, and 67 cases of IBC in SD rats (Table 2).

\section{Immunohistochemical analyses}

Immunohistochemical analyses were performed as previously described ${ }^{16}$. After antigen retrieval, tissue sections were dipped in methanol- $\mathrm{H}_{2} \mathrm{O}_{2}(0.3 \%(\mathrm{v} / \mathrm{v}))$ for $30 \mathrm{~min}$. After washing with PBS, the sections were incubated with primary antibodies. After washing with PBS three times for 5 min, Histofine Simple Stain Rat Max PO was applied to the tissue sections. After washing with PBS three times, the localization of the immune complexes was visualized by liquid $\mathrm{DAB}+$ as a brown precipitate. To evaluate Twistl expression in association with reproductive hormonal changes, tissue microarray slides were constructed (core diameter, $7 \mathrm{~mm}$ ) using a tissue microprocessor (KIN-1, Azumaya medical instruments, Tokyo, Japan). We quantified Twistl expression over the area of each core and calculated the positive ratios in the periductal and TDLU areas. In tissue specimens obtained after chemically induced mammary carcinoma, all tumors were stained by $\alpha$-SMA to confirm the diagnosis of DCIS and an intraductal component of carcinoma when the area was larger than $2 \times 2 \mathrm{~mm}^{2}$. In breast carcinomas, the threshold for Twistl-positivity in mesenchymal cells was defined as more than $1 \%$ in accordance with the Allred scor- 
ing system ${ }^{17}$. The presence of more than $1 \%$ Twist1-positive epithelia was also defined as positive. These examinations were performed with nuclear counterstaining using hematoxylin. The NIH3T3 cell line was used as the positive control for Twistl immunohistochemistry. The cell pellets of NIH3T3 were fixed in PBS-buffered 10\% formalin, and then the pellets were processed to prepare paraffin-embedded tissue sections ${ }^{17}$. These sections were used to verify excellent staining conditions prior to staining of the tissue sections of mammary glands. Twistl was detected in the nuclei of NIH3T3 (data not shown). Simultaneously, whole cell lysates of NIH3T3 were examined by western blot ${ }^{17}$. A band was seen at approximately $28 \mathrm{kDa}$, indicating that the antibody recognized a protein of the correct size (data not shown).

For triple staining of $\alpha$-SMA, Twist1, and AE1/3, an antibody against $\alpha$-SMA was first applied to the slides, and anti-mouse $\operatorname{IgG}(\mathrm{H}+\mathrm{L})$ conjugated to alkaline phosphatase was used for visualization in combination with the BCIP/ NBT substrate. After high-temperature treatment for antigen retrieval and inactivation of the immune complexes, the sections were incubated with an antibody against Twistl, followed by treatment with the Histofine Simple Stain Rat Max PO. The localization of Twistl was visualized using liquid $\mathrm{DAB}+$. Finally, high temperature treatment for simultaneous antigen retrieval and inactivation of immune complexes was performed via incubation with an antibody against AE1/3, followed by treatment with Histofine Simple Stain Rat Max PO. The localization of AE1/3 was visualized using TACS Blue labeling.

\section{Statistical analyses}

Statistical analyses were performed using one-way analysis of variance (ANOVA) and a Tukey-Kramer test. Differences were considered significant when $p<0.05$. The data were expressed as means \pm SEM $(n=3-6)$ unless otherwise specified. These analyses were performed using GraphPad Prism 7 Software (GraphPad Software, La Jolla, CA, USA).

\section{Results}

Expression of Twistl in the breast of adolescent, pregnant, lactating and elderly rats

Twistl-positive mesenchymal cells were prevalent in the periductal stroma in adolescent and pregnant rats (Fig. 1A, B). In the terminal duct lobular unit (TDLU), Twist1-positive mesenchymal cells were abundant in pregnant and elderly rats (Fig. 1A, C). In lactating rats, there were few Twist1-positive mesenchymal cells in the periductal stroma and TDLU. The distributions of Twist1-positive mesenchymal cells were significantly altered in rats of various ages and hormonal statuses.

\section{Twist1 was detected diffusely in the mesenchymal cells of mammary FA}

Twist1-positive mesenchymal cells were observed in FA in F1 hybrid rats (7/7) and SD rats (2/2). Mesenchymal cells that were negative for myoepithelial markers ( $\alpha$-SMA, p63, and CD10), and an epithelial marker (AE1/3) were diffusely positive for Twist1 in pericanalicular (Fig. 2), organoid, and hyalinized subtypes (data not shown). Regardless of histological subtypes, the ratio of Twistl positivity ranged between 50 and $70 \%$.

\section{Expression of Twist1 in mesenchymal cells favored invasive components of chemically induced breast carcinoma in rats}

Histopathology of IBC and DCIS in an animal model is different from that in a typical human; however, it shares characteristic features $11,18,19$. DCIS is characterized by the presence of lining myoepithelial cells, and IBC is characterized by the absence of lining myoepithelia. Twist1-positive mesenchymal cells were not seen in DCIS (0/1) and intraductal components $(0 / 8$; Fig. $3 \mathrm{~A}, \mathrm{C})$. In IBC with intraductal component, Twist1-positive cancer-associated mesenchymal cells were detected in the IBC components $(3 / 8$, $38 \%$; Fig. 3C). In IBC only, there was a higher incidence of Twistl-positive cancer-associated mesenchymal cells (45/67, $67 \%$; Fig. 3B, C). Twist1-positive mesenchymal cells were significantly greater in IBC than in the intraductal component (Fig. 3C). There were no Twist1-positive epithelia in the intraductal component or IBC (data not shown).

\section{Discussion}

We showed that Twistl was expressed in the mesenchymal cells of non-tumor-bearing tissues at various life stages (i.e., adolescence, pregnancy, lactation, and elderly) as well as in FA in F1 hybrid rats. This F1 hybrid rat model (Brown Norway x Fischer 344) is recommended by the National Institute of Aging in the USA to reduce age-related disease and increase life $\operatorname{span}^{20}$. Twist1, a transcriptional regulator of epithelial-mesenchymal transition, has been shown to impair abnormal craniofacial structures and polydactyly in the hind limb ${ }^{6}$. Immunostaining of the rat fetus revealed that Twistl was expressed in the mesenchymal cells of extremities (data not shown), which is consistent with the phenotypes of humans and mice. These results suggest the biological role of Twistl in tissue remodeling for various organs. To address the possible role of Twistlpositive mesenchymal cells, we examined the expression of Twistl at various life stages in mammary glands. Twist1positive mesenchymal cells were observed in the periductal stroma of adolescent and pregnant rats (Fig. 1A, B). There was an emergence of Twist1-positive mesenchymal cells at the TDLU of pregnant and elderly rats (Fig. 1A, C). These results suggest that Twist1-positive mesenchymal cells in elderly rats altered expression levels of Twistl in the TDLU or migrated from a different location such as the periductal stroma. In pregnant rats, there were high levels of Twistlpositive mesenchymal cells in the periductal stroma and TDLU. At this stage, the secretions of several biologically active substances were markedly increased via degradation of the extracellular matrix and angiogenic remodeling that 

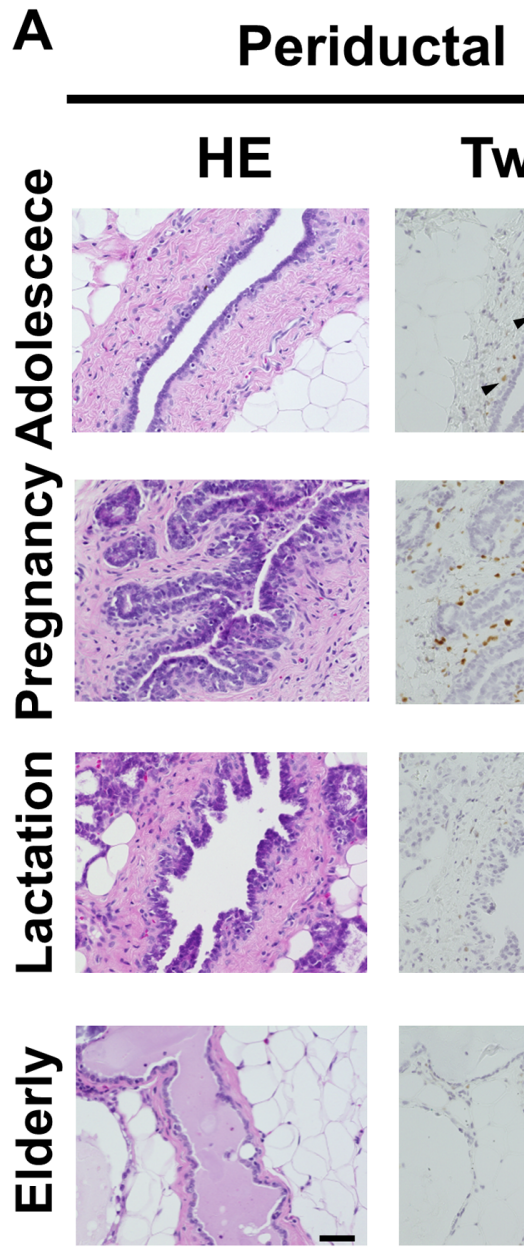

Twist1
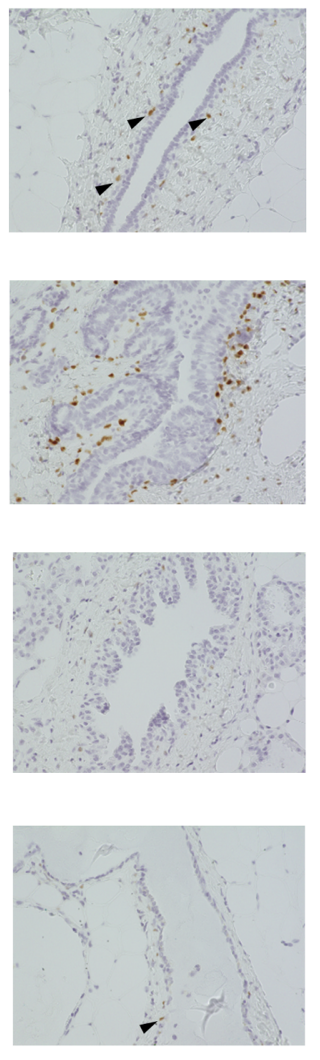

\section{TDLU}

B Periductal

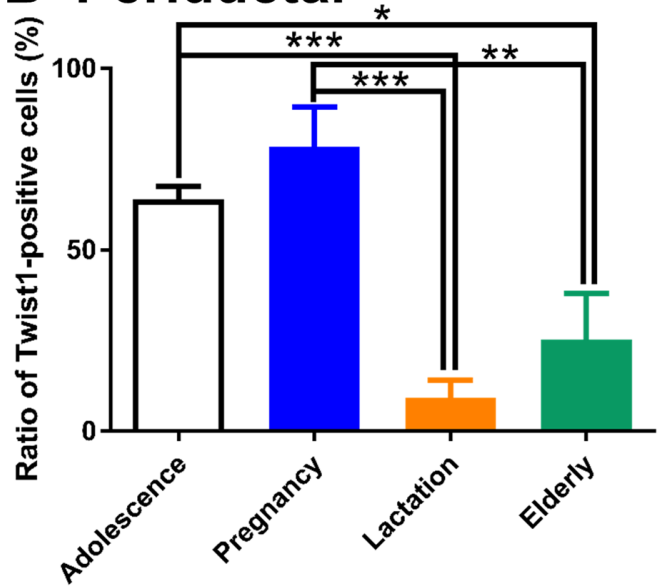

Terminal Duct Lobular Unit (TDLU)

HE
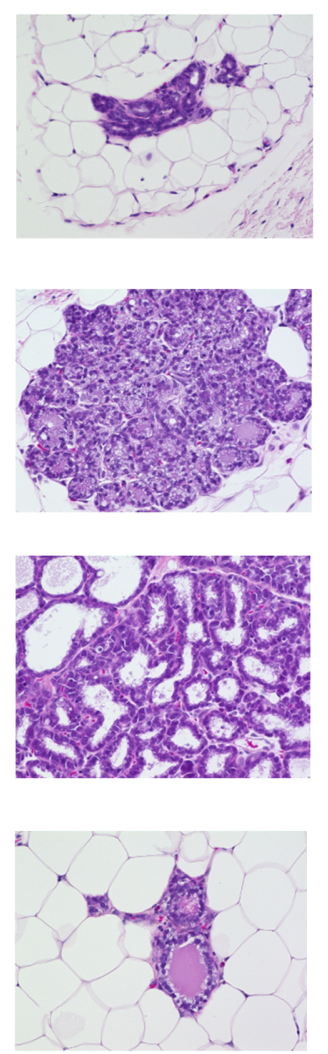

Twist1
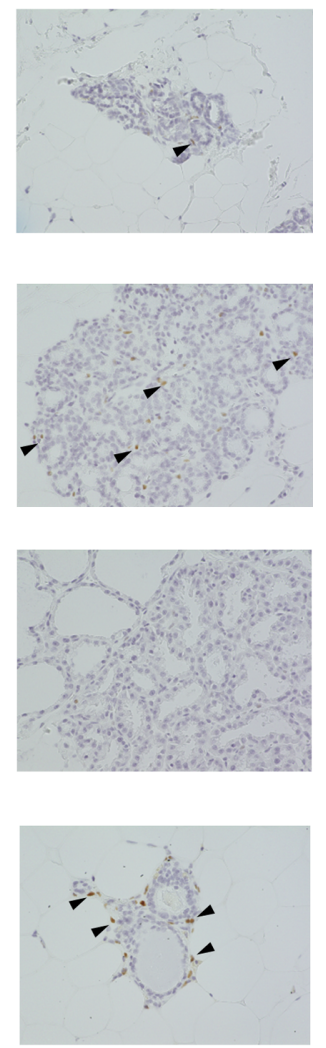

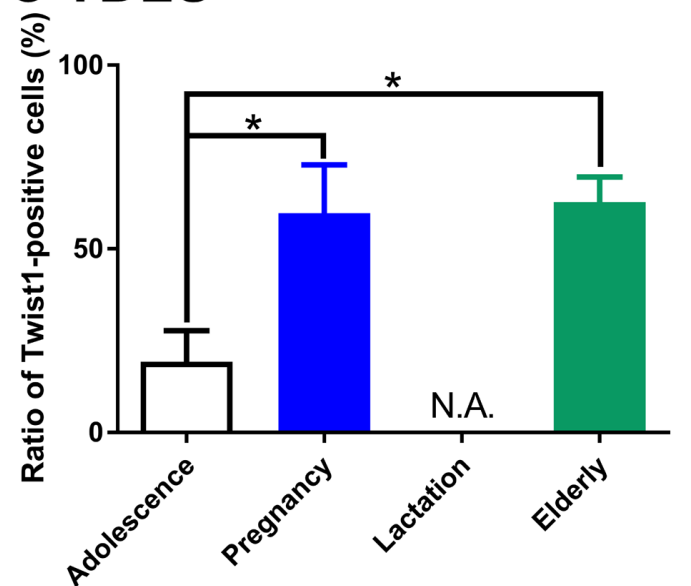

Fig. 1. Expression of Twistl in the breast of adolescent, pregnant, lactating and elderly rats. (A) Representative images of the periductal area and terminal duct lobular unit (TDLU) are shown for adolescent, pregnant, lactating, and elderly rats (bar, $50 \mu \mathrm{m}$ ). In the periductal area, Twist1-positive mesenchymal cells predominantly emerged in the adolescent and pregnant stages. In the TDLU, Twist1-positive mesenchymal cells were observed in the pregnant and elderly stages (arrowheads, Twistl-positive cells). (B) In the periductal area, there were significant differences in the Twist1-positive ratio among the adolescent, pregnant, and elderly stages. (ANOVA, $\mathrm{p}<0.0001 ;{ }^{*} \mathrm{p}<0.05$ $v s$ the elderly stage; $* * \mathrm{p}<0.01 v s$ the elderly stage; $* * * \mathrm{p}<0.001 v s$ the lactating stage). (C) In the TDLU, there were significant differences in the Twist1-positive ratio among the pregnant, elderly and adolescent stages (ANOVA, $\mathrm{p}=0.0005 ;{ }^{*} \mathrm{p}<0.05 v s$ the adolescence). N.A. stands for not available due to the disappearance of mesenchymal cells during the development of lactation. 
HE

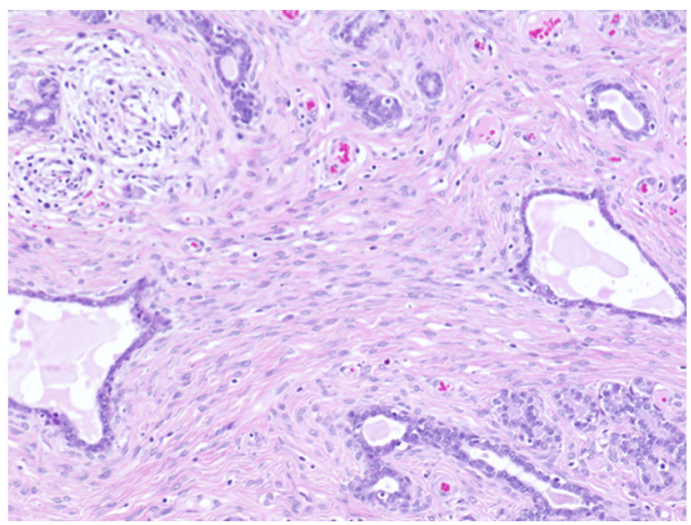

p63

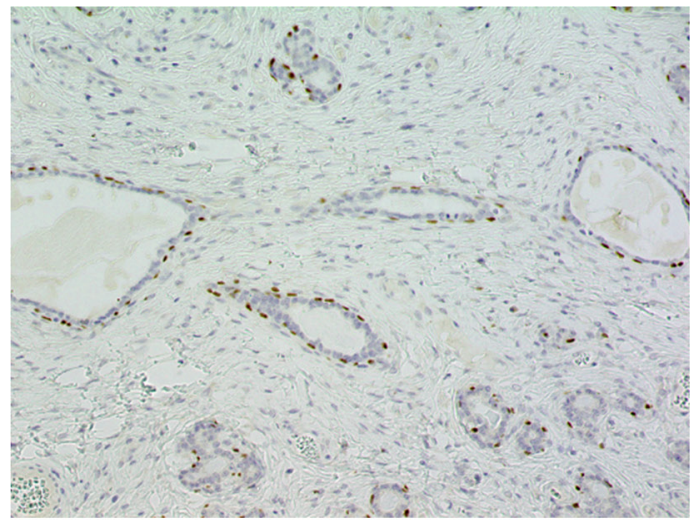

CD10

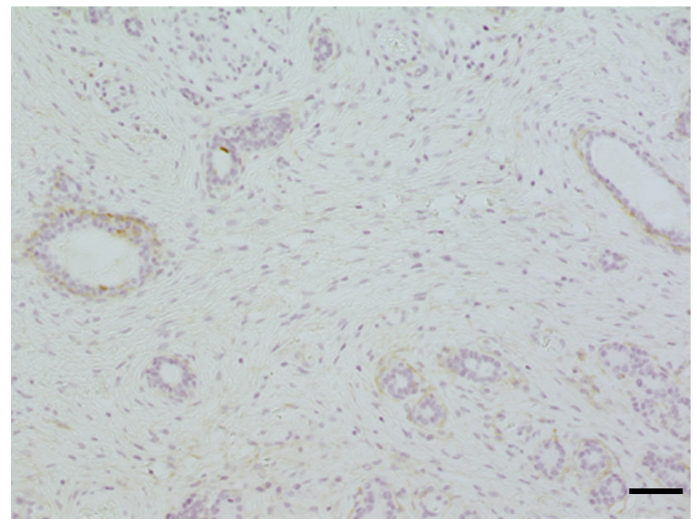

Twist1

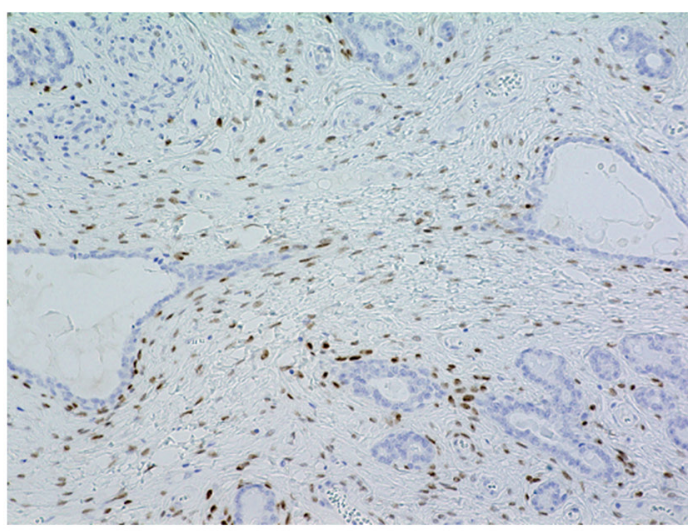

$\alpha$-SMA

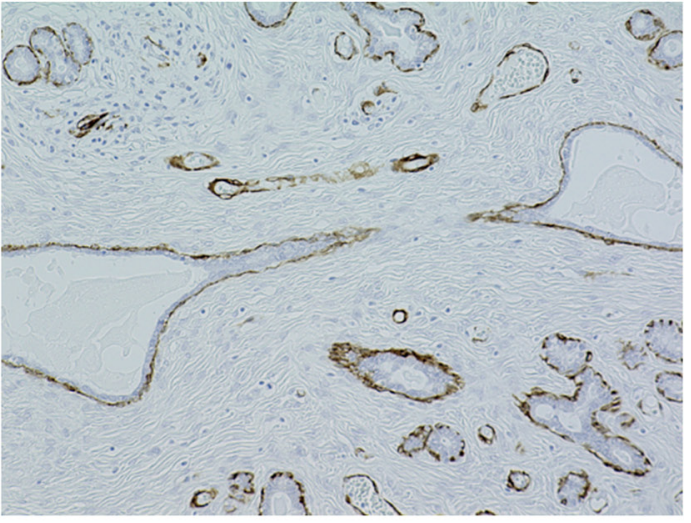

AE1/3

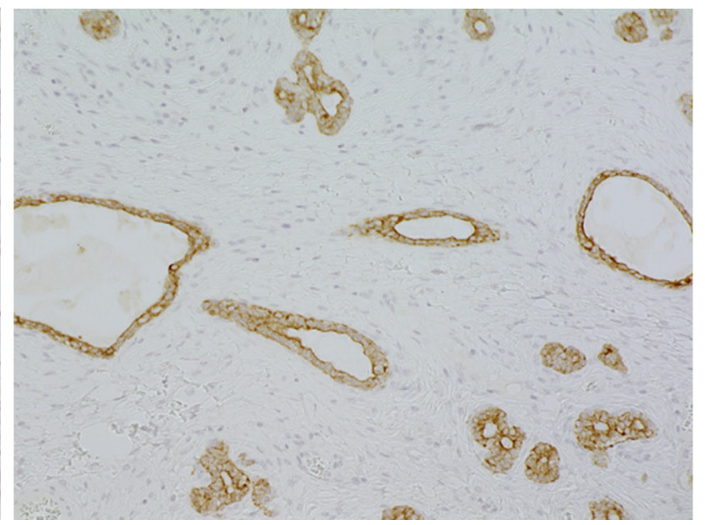

Fig. 2. Twist1 was diffusely expressed in fibroadenoma (FA) in the mammary glands of rats. Representative images of immunohistochemistry in FA. Mesenchymal cells in FA were positive for Twist1 but were negative for myoepithelial markers (p63, $\alpha$-smooth muscle actin ( $\alpha$-SMA), and CD10) and an epithelial marker (AE1/3) (bar, $50 \mu \mathrm{m})$.

may induce the expression of Twist1 in mesenchymal cells.

Although FA is the most common benign mammary gland neoplasm in rats, spontaneous FA was frequently observed at the elderly stage and was rare at the childbearing stage $^{7-9,11,12,21}$. In Fischer 344 rats, the rates of FA occurrence were reported to be $48 \% 0^{8}, 16 \%{ }^{9}, 9 \%{ }^{11}$, and $12 \%{ }^{12}$. In Brown Norway rats, the rate of FA occurrence was reported to be $11 \%{ }^{11}$. In SD rats, the rates of FA occurrence were re- ported to be $67 \%^{8}$ and $19 \%$. In addition to the high incidence of FA, pituitary gland adenoma was also commonly observed in Fischer 344 rats $\left(45 \% \%^{8}, 29 \%{ }^{9}, 26 \%{ }^{12}\right)$ and SD rats $\left(39 \%{ }^{8}\right.$ and $\left.49 \%{ }^{7}\right)$. While the production of prolactin from the pituitary adenoma has been demonstrated, the coincidence of FA and pituitary adenoma is not evident ${ }^{8}$. Although FA is a common spontaneous tumor in several strains, the pathogenesis remains unclear. In this study, the detection 


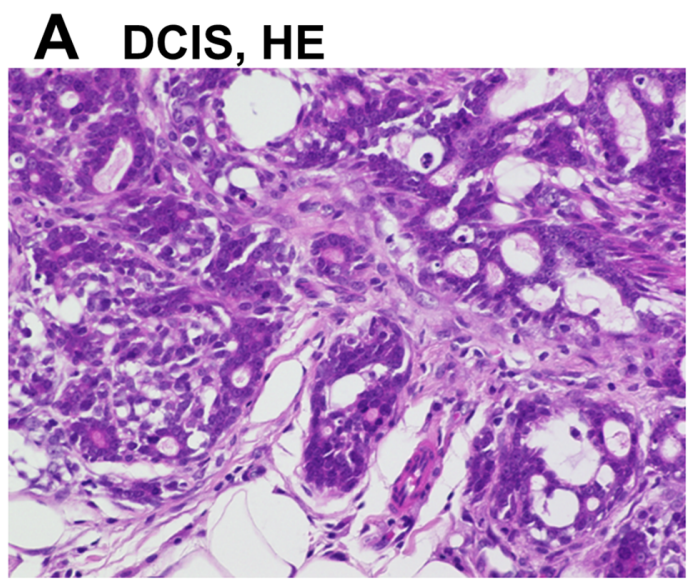

$$
\begin{aligned}
& \text { a-SMA (dark blue), } \\
& \text { AE1/3 (bright blue), } \\
& \text { Twist1 (brown) }
\end{aligned}
$$

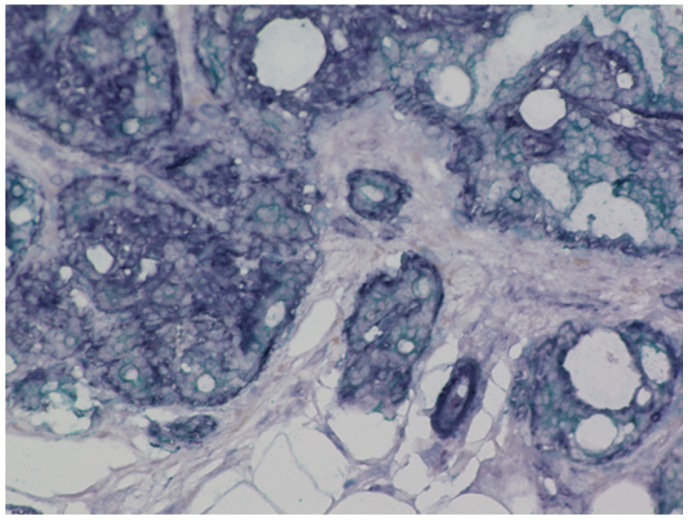

\section{B IBC, HE}
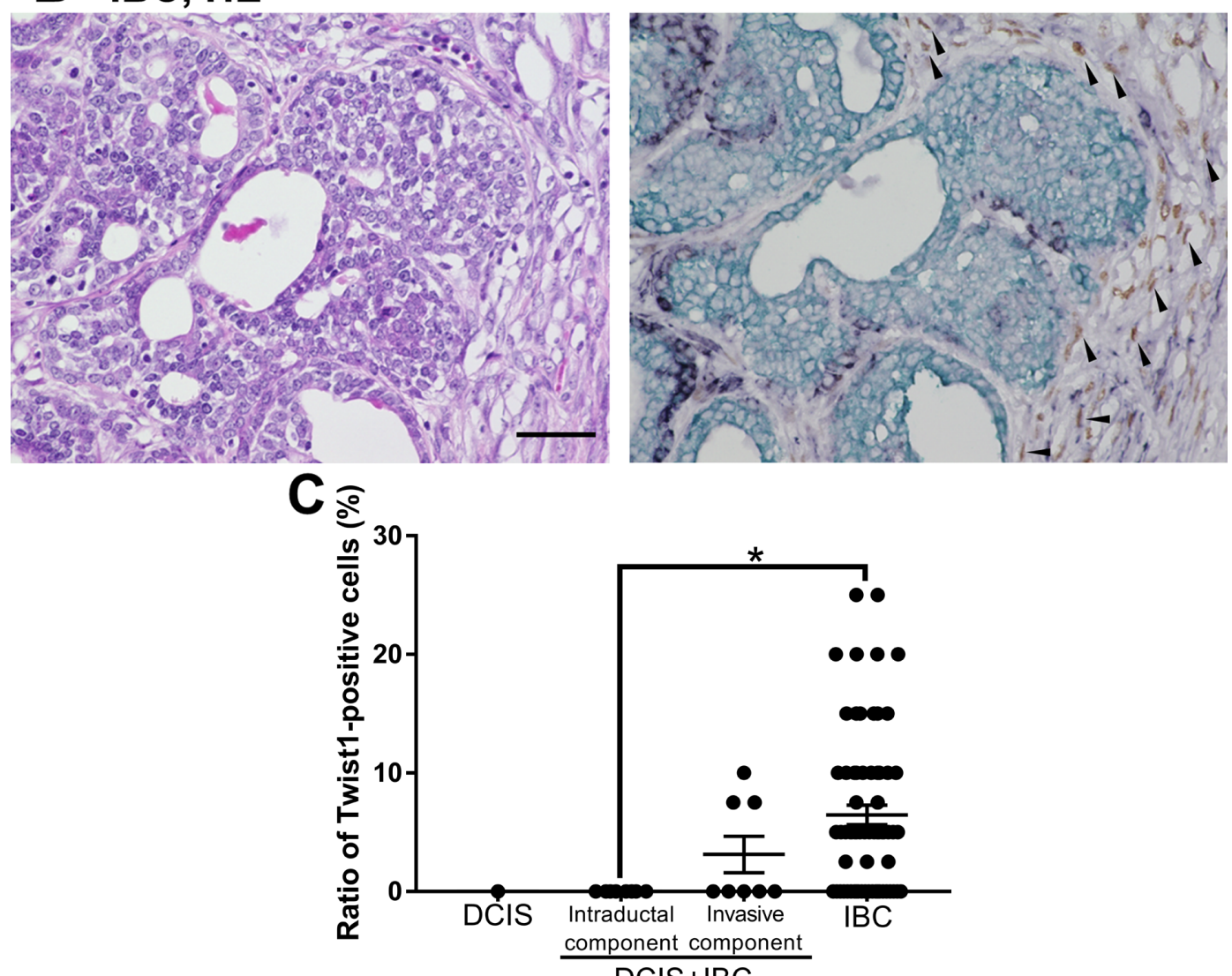

$\mathrm{DCIS}+\mathrm{IBC}$

Fig. 3. Expression of Twistl in mesenchymal cells favored invasive components of chemically induced breast carcinoma (IBC) in rats. Representative images of the intraductal component of a carcinoma and IBC are shown. $\alpha$-smooth muscle actin $(\alpha$-SMA), a myoepithelial marker, was visualized as dark blue; AE1/3, an epithelial marker (ductal carcinoma component), was visualized as bright blue, and Twist1 was visualized as brown. (A) There was only a limited number of Twist1-positive cancer-associated mesenchymal cells (brown) in the stroma of the intraductal component of the carcinoma, confirmed by the presence of $\alpha$-SMA (dark blue). (B) There were many Twist1positive and $\alpha$-SMA negative cancer-associated mesenchymal cells (arrow heads) in the desmoplastic stroma of the IBC, confirmed by the absence of $\alpha$-SMA-positive myoepithelial cells (bar, $50 \mu \mathrm{m}$ ). (C) The ratio of Twistl-positive mesenchymal cells is shown. The mesenchymal cells of the IBC expressed significantly greater number of Twist 1 than the intraductal components did (ANOVA, $p=0.0267$; ${ }^{*} \mathrm{p}<0.05$ vs IBC). 
of Twist1-positive mesenchymal cells in the TDLU at the elderly stage but not at the adolescent stage (Fig. 1) suggests the involvement of preexisting Twistl-positive mesenchymal cells in the histogenesis of TDLU-derived FA in elderly rats.

Twist1-positive mesenchymal cells were significantly more prominent in the stromal elements of IBC than in the intraductal component and DCIS, consistent with a previous report in a case of gastric cancer ${ }^{22}$. A correlation between protein expression of Twist1 in epithelia and poor prognosis in breast carcinomas has been described ${ }^{23-27}$. In addition to the biological impact on prognosis, the expression of Twist1 in mammary epithelial cells was shown to enhance the recruitment of macrophages to remodel the matrices ${ }^{28}$, suggesting the importance of cross-talk between Twist1 and mesenchymal structures. Therefore, we examined the expression levels of Twistl in the epithelial elements of adenocarcinomas. However, we did not observe epithelialmesenchymal transition via HE staining or Twist1-positive carcinoma via immunohistochemistry (data not shown).

In conclusion, we demonstrated that Twistl-positive mesenchymal cells were predominantly located in the periductal area in the adolescent and pregnant stages and at the TDLU in the pregnant and elderly stages. Cancer-associated mesenchymal cells also expressed Twistl in IBC components. These results suggest the biological role of Twistl in mesenchymal cells. Further study may shed light on the functional role of Twistl in tissue structures.

Disclosure of Potential Conflicts of Interest: The authors do not have any conflicts of interest.

Acknowledgements: This work was supported in part by Grants-in-Aid for Young Scientists (B; 23790440, 25860292; to YO) from the Japan Society for the Promotion of Science (JSPS) and a Grant-in-Aid for JSPS Fellows (to HN). The authors wish to thank Nobuaki Misawa for the preparation of tissue sections and Dr. Hu Qian for the generous gift of paraffin-embedded mammary gland neoplasms.

\section{References}

1. Loke BN, Md Nasir ND, Thike AA, Lee JYH, Lee CS, Teh BT, and Tan PH. Genetics and genomics of breast fibroadenomas. J Clin Pathol. 71: 381-387. 2018. [Medline] [CrossRef]

2. Lakhani SR, Ellis IO, Schnitt SJ, Tan PH, van de Vijver MJ. WHO Classification of Tumours of the Breast. World Health Organization, Lyon. 2012.

3. Pareja F, Geyer FC, Kumar R, Selenica P, Piscuoglio S, Ng CKY, Burke KA, Edelweiss M, Murray MP, Brogi E, Weigelt B, and Reis-Filho JS. Phyllodes tumors with and without fibroadenoma-like areas display distinct genomic features and may evolve through distinct pathways. NPJ Breast Cancer. 3: 40. 2017. [Medline] [CrossRef]

4. Tan BY, Acs G, Apple SK, Badve S, Bleiweiss IJ, Brogi E, Calvo JP, Dabbs DJ, Ellis IO, Eusebi V, Farshid G, Fox SB,
Ichihara S, Lakhani SR, Rakha EA, Reis-Filho JS, Richardson AL, Sahin A, Schmitt FC, Schnitt SJ, Siziopikou KP, Soares FA, Tse GM, Vincent-Salomon A, and Tan PH. Phyllodes tumours of the breast: a consensus review. Histopathology. 68: 5-21. 2016. [Medline] [CrossRef]

5. Wiseman BS, and Werb Z. Stromal effects on mammary gland development and breast cancer. Science. 296: 10461049. 2002. [Medline] [CrossRef]

6. Ansieau S, Morel AP, Hinkal G, Bastid J, and Puisieux A. TWISTing an embryonic transcription factor into an oncoprotein. Oncogene. 29: 3173-3184. 2010. [Medline] [CrossRef]

7. Chandra M, Riley MG, and Johnson DE. Spontaneous neoplasms in aged Sprague-Dawley rats. Arch Toxicol. 66: 496-502. 1992. [Medline] [CrossRef]

8. Dinse GE, Peddada SD, Harris SF, and Elmore SA. Comparison of NTP historical control tumor incidence rates in female Harlan Sprague Dawley and Fischer 344/N Rats. Toxicol Pathol. 38: 765-775. 2010. [Medline] [CrossRef]

9. Goodman DG, Ward JM, Squire RA, Chu KC, and Linhart MS. Neoplastic and nonneoplastic lesions in aging F344 rats. Toxicol Appl Pharmacol. 48: 237-248. 1979. [Medline] [CrossRef]

10. Marxfeld H, Staedtler F, and Harleman JH. Gene expression in fibroadenomas of the rat mammary gland in contrast to spontaneous adenocarcinomas and normal mammary gland. Exp Toxicol Pathol. 58: 145-150. 2006. [Medline] [CrossRef]

11. Morii S, Tsubura A, Fujii T, and Oishi Y. [Histopathology of mammary tumors in mice and rats]. Jikken Dobutsu. 33: 47-59. 1984.(in Japanese) [Medline]

12. Takanobu K, Aiso S, Umeda Y, Senoh H, Saito M, Katagiri T, Ikawa N, Ishikawa $\mathrm{H}$, Mine T, Take M, Haresaku M, Matsumoto M, and Fukushima S. [Background data of spontaneous tumors in F344/DuCrlCrlj rats]. Sangyo Eiseigaku Zasshi. 57: 85-96. 2015.(in Japanese) [Medline] [CrossRef]

13. Hu Q, Akatsuka S, Yamashita Y, Ohara H, Nagai H, Okazaki Y, Takahashi T, and Toyokuni S. Homozygous deletion of CDKN2A/2B is a hallmark of iron-induced high-grade rat mesothelioma. Lab Invest. 90: 360-373. 2010. [Medline] [CrossRef]

14. Imai T, Cho YM, Hasumura M, and Hirose M. Enhancement by acrylamide of N-methyl-N-nitrosourea-induced rat mammary tumor development-possible application for a model to detect co-modifiers of carcinogenesis. Cancer Lett. 230: 25-32. 2005. [Medline] [CrossRef]

15. Nagai H, Okazaki Y, Chew SH, Misawa N, Yasui H, and Toyokuni S. Deferasirox induces mesenchymal-epithelial transition in crocidolite-induced mesothelial carcinogenesis in rats. Cancer Prev Res (Phila). 6: 1222-1230. 2013. [Medline] [CrossRef]

16. Okazaki Y, Kono I, Kuriki T, Funahashi S, Fushimi S, Iqbal M, Okada S, and Toyokuni S. Bovine lactoferrin ameliorates ferric nitrilotriacetate-induced renal oxidative damage in rats. J Clin Biochem Nutr. 51: 84-90. 2012. [Medline] [CrossRef]

17. Okazaki Y, Nagai H, Chew SH, Li J, Funahashi S, Tsujimura T, and Toyokuni S. CD146 and insulin-like growth factor 2 mRNA-binding protein 3 predict prognosis of asbestosinduced rat mesothelioma. Cancer Sci. 104: 989-995. 2013. [Medline] [CrossRef] 
18. Goldschmidt M, Peña L, Rasotto R, and Zappulli V. Classification and grading of canine mammary tumors. Vet Pathol. 48: 117-131. 2011. [Medline] [CrossRef]

19. Marques R, Vaz CV, Maia CJ, Gomes M, Gama A, Alves G, Santos CR, Schmitt F, and Socorro S. Histopathological and in vivo evidence of regucalcin as a protective molecule in mammary gland carcinogenesis. Exp Cell Res. 330: 325335. 2015. [Medline] [CrossRef]

20. Fannin J, Rice KM, Thulluri S, Dornon L, Arvapalli RK, Wehner P, and Blough ER. Age-associated alterations of cardiac structure and function in the female $\mathrm{F} 344 \mathrm{xBN}$ rat heart. Age (Dordr). 36: 9684. 2014. [Medline] [CrossRef]

21. Ikezaki S, Takagi M, and Tamura K. Natural occurrence of neoplastic lesions in young sprague-dawley rats. J Toxicol Pathol. 24: 37-40. 2011. [Medline] [CrossRef]

22. Sung CO, Lee KW, Han S, and Kim SH. Twistl is up-regulated in gastric cancer-associated fibroblasts with poor clinical outcomes. Am J Pathol. 179: 1827-1838. 2011. [Medline] [CrossRef]

23. Alkatout I, Wiedermann M, Bauer M, Wenners A, Jonat W, and Klapper W. Transcription factors associated with epithelial-mesenchymal transition and cancer stem cells in the tumor centre and margin of invasive breast cancer. Exp Mol Pathol. 94: 168-173. 2013. [Medline] [CrossRef]
24. Gort EH, Suijkerbuijk KP, Roothaan SM, Raman V, Vooijs M, van der Wall E, and van Diest PJ. Methylation of the TWIST1 promoter, TWIST1 mRNA levels, and immunohistochemical expression of TWIST1 in breast cancer. Cancer Epidemiol Biomarkers Prev. 17: 3325-3330. 2008. [Medline] [CrossRef]

25. Martin TA, Goyal A, Watkins G, and Jiang WG. Expression of the transcription factors snail, slug, and twist and their clinical significance in human breast cancer. Ann Surg Oncol. 12: 488-496. 2005. [Medline] [CrossRef]

26. Soini Y, Tuhkanen H, Sironen R, Virtanen I, Kataja V, Auvinen P, Mannermaa A, and Kosma VM. Transcription factors zebl, twist and snail in breast carcinoma. BMC Cancer. 11: 73. 2011. [Medline] [CrossRef]

27. van Nes JG, de Kruijf EM, Putter H, Faratian D, Munro A, Campbell F, Smit VT, Liefers GJ, Kuppen PJ, van de Velde $\mathrm{CJ}$, and Bartlett JM. Co-expression of SNAIL and TWIST determines prognosis in estrogen receptor-positive early breast cancer patients. Breast Cancer Res Treat. 133: 49-59. 2012. [Medline] [CrossRef]

28. Low-Marchelli JM, Ardi VC, Vizcarra EA, van Rooijen N, Quigley JP, and Yang J. Twist1 induces CCL2 and recruits macrophages to promote angiogenesis. Cancer Res. 73: 662-671. 2013. [Medline] [CrossRef] 